\title{
HUBUNGAN PERSEPSI MAHASISWA PADA E-MODULE MATERI CERMIN CEKUNG DENGAN KETERAMPILAN PROSES SAINS DASAR
}

\author{
Neng Ria Nasih ${ }^{1}$, Syahriadi Sinaga ${ }^{2}$ \\ Program Studi Pendidikan Fisika, Universitas Jambi ${ }^{1}$ \\ Program Studi Teknik Informatika, Universitas Asahan ${ }^{2}$ \\ Email: nasihnengria28@gmail.com ${ }^{1}$
}

\begin{abstract}
Abstrak
Persepsi yang dimiliki mahasiswa berbeda-beda tergantung dengan apa yang sedang diamati oleh mahasiswa. Pada era modern saat ini maka dapat memanfaatkan teknologi sebagai media untuk pembelajaran dan penilaian. Sejalan dengan revolusi 4.0 yang mana hampir semua telah memanfaatkan teknologi. Dengan itu penelitian ini bertujuan untuk melihat hubungan persepsi mahasiswa dengan keterampilan proses sains dasar mahasiswa pada materi cermin cekung dengan memanfaatkan teknologi dalam pembelajarannya. Metode yang digunakan dalam penelitian ini adalah metode penelitian asosiatif kuantitatif dengan desain penelitian korelasional. Teknik penelitian yang digunakan adalah teknik purposive sampling. Hasil data yang telah dianalisis menghasilkan bahwa pada keterampilan proses sains dasar mahasiswa terhadap penggunaan $e$-module materi cermin cekung menghasilkan persentase $41.2 \%$ dengan kategori sangat baik dan persepsi mahasiswa terhadap penggunaan e-module materi cermin cekung adalah sebesar $61.8 \%$ dengan kategori sangat baik. Berdasarkan nilai signifikansi yang dihasilkan maka dapat dikatakan bahwa hubungan pada keterampilan proses sains dasar mahasiswa dengan persepsi mahasiswa terhadap penggunaan $e$ module materi cermin cekung adalah sangat kuat dengan pearson correlation 0.958 dan signifikansi sebesar 0.000 .
\end{abstract}

Kata Kunci : Persepsi, e-module, Cermin Cekung, Keterampilan Proses Sains

\begin{abstract}
Perceptions held by students differ depending on what is being observed by students. In the modern era, it can utilize technology as a medium for learning and assessment. In line with the 4.0 revolution which almost all have used technology. With this research aims to see the relationship between students 'perceptions with students' basic science process skills in concave mirror material by utilizing technology in their learning. The method used in this study is a quantitative associative research method with a correlational research design. The research technique used was purposive sampling technique. The results of the data that have been analyzed produce that the basic science process skills of students towards the use of concave mirror material e-modules produce a percentage of $41.2 \%$ with a very good category and the students' perception of the use of concave mirror material e-modules is $61.8 \%$ with very good categories. Based on the significance value generated, it can be said that the relationship on students 'basic science process skills with the students' perception of the use of concave mirror material e-modules is very strong with the Pearson correlation of 0.958 and a significance of 0.000 .
\end{abstract}

Key Words : Perception, e-module, Concave Mirror, Scince Process Skill

\section{PENDAHULUAN}

Fisika merupakan pembelajaran yang bersifat abstrak, sehingga sulit dalam penerapannya. Physics is an abstract subject that requires high-level thinking skills that make it difficult for students to understand the topic of Physics [1]. Anggapan bahwa mata pelajaran fisika merupakan mata pelajaran yang menakutkan dan sulit maka akan menyebabkan mahasiswa menjadi pesimis, apatis dan malas dalam mempelajarinya [2]. Pembelajaran fisika sering ditemukan dalam kehidupan sehari-hari. Penerapan mata pelajaran fisika sering ditemukan sehari-hari karena fisika merupakan salah 
satu mata pelajaran yang berhubungan dengan berbagai konsep ilmiah [3]. Pembelajaran fisika sangat erat kaitannya dengan pembelajaran yang sulit. Ilmu fisika sampai saat ini masih dianggap mata pelajaran yang sulit karena karakteristik fisika yang abstrak [4]. Untuk memahami pembelajaran fisika perlu dikuasai pemahaman yang tinggi dalam konsepkonsep fisika. Dalam mempelajari mata pelajaran fisika harus handal dalam logika dan juga harus handal dalam matematikanya, oleh karena itu mata pelajaran fisika kurang disukai oleh peserta didik [5]. Minat belajar fisika mahasiswa yang rendah menyebabkan kurang suka membaca buku, malas mengerjakan tugas, dan hal-hal yang berkenaan dengan fisika maka mahasiswa akan kurang tertarik untuk mempelajarainya [6]. Science is nothing but a focus on theoretical explanation because it is likely that there will be many differences of opinion according to individual observations that require direct practice [7].

Kecenderungan mahasiswa dalam menerima atau menolak pembelajaran bergantung pada ketertarikan mahasiswa terhadap pembelajaran yang akan dipelajari. Faktor pengaruh siswa memiliki ketertarikan ataupun tidak antara sikap terhadap mata pelajaran dapat diketahui dari kecenderungan siswa yang menerima ataupun menolak ketika diminta untuk mengerjakan soal yang diberikan [8]. Ketertarikan dalam mempelajari fisika dapat dilakukan dengan cara praktikum, karena dalam aktivitas praktikum mahasiswa dapat dengan mudah dalam memahami konsep-konsep fisika. Praktikum dapat melatih keterampilan proses sains mahasiswa. Keterampilan proses sains merupakan keterampilan yang dimiliki mahasiswa yang bukan hanya mementingkan hasilnya saja melainkan proses juga akan sangat dibutuhkan. In addition to applying conceptual understanding, process skills can also be used to find problem solving [9]. Keterampilan proses sains merupakan kemampuan dalam mengolah tindakan sekaligus pemikiran ilmiah guna mengembangkan pemahaman konsep ilmiah untuk menunjang kemampuankemampuan berikutnya [10]. Science process skills can be developed by carrying out practical activities. In developing process skills, practicum methods can be used [11]. Keterampilan proses sains mahasiswa terdiri dari keterampilan proses sains dasar dan terintegritas atau terpadu. Agar menghasilkan keterampilan proses sains yang optimal, maka seharusnya dikuasai terlebih dahulu keterampilan proses sains dasar sehingga untuk keterampilan proses sains terintegritas mudah untuk dipahami. So it can be said that if students do not master basic process skills and are integrated together it will be difficult for students to develop higher abilities and this will affect students later when they become teachers [12]. Seorang pendidik professional harus memiliki sejumlah syarat seperti standar kompetensi pendidik yang sudah ditetapkan [13]. Keterampilan proses sains dasar dan terpadu sangat dibutuhkan bagi calon guru fisika, karena selain dapat membantu ketika penyelidikan ilmiah, keterampilan ini juga berguna ketika proses mengajar [14]. Keterampilan proses sains mencakup dua kelompok yaitu keterampilan proses dasar dan keterampilan proses terintegrasi. Keterampilan proses dasar sains di antaranya: observasi, komunikasi, klasifikasi, pengukuran, kesimpulan, prediksi. Dan keterampilan proses terintegrasi di antaranya: identifikasi variabel, membuat tabel data, membuat grafik, menggambarkan hubungan antar variabel, memperoleh dan memproses data, analisis investigasi, membuat hipotesis, mendefinisikan variabel secara operasional, merancang investigasi, dan 
melakukan percobaan. Upaya dalam meningkatkan keterampilan proses mahasiswa adalah dengan pengembangan penuntun berbasis keterampilan proses sains. Keterampilan proses sains dapat dilihat dengan bagaimana mahasiswa dalam melakukan kegiatan praktikum. Salah satunya adalah praktikum cermin cekung. Agar pemahaman akan praktikum dapat berjalan dengan optimal maka sebagai calon pendidik, dituntut untuk dapat menguasai keterampilan proses sains. Dengan memanfaatkan teknologi maka dapat membantu dalam mengoptimalkan pembelajaran dan pengukuran keterampilan proses sains (KPS).

Pada era modern saat ini maka dapat memanfaatkan teknologi sebagai media untuk pembelajaran dan penilaian. Sejalan dengan revolusi 4.0 yang mana hampir semua telah memanfaatkan teknologi. The term Industrie 4.0 means the fourth industrial revolution. It combines the technical advances that have emerged to improve the industry by facing global challenges [15]. Dengan itu teknologi dalam pendidikan tentu akan memberikan dampak yang positif baik pada ekonomi maupun pendidikan. Pendidikan di Indonesia telah terintegrasi dengan baik dan perlu pengembangan lebih lanjut [16]. The industrial revolution 4.0 not only paves the way for economic activity but also provides opportunities for education through learning technology one of which is cellular learning is learning that can be simplified through the use of mobile devices [17]. Dengan itu penelitian ini bertujuan untuk melihat hubungan persepsi mahasiswa pada e-module pada materi cermin cekung dengan keterampilan proses sains dasar mahasiswa dengan memanfaatkan teknologi dalam pembelajarannya. Persepsi mahasiswa terjadi jika diberi stimulus dengan melibatkan pengalamannya. Persepsi dapat terjadi jika seseorang melihat objek, stimulus atau peristiwa dengan melibatkan pengalaman yang ada, persepsi yang ada dalam diri mahasiswa akan mempengaruhi minat mahasiswa untuk melakukan suatu aktivitas termasuk belajar [18]. Persepsi yang dimiliki mahasiswa berbeda-beda tergantung dengan apa yang sedang diamati oleh mahasiswa. Persepsi mahasiswa terkadang muncul ketika proses pembelajaran berlangsung. Mahasiswa akan memberikan persepsinya berdasarkan apa yang dilakukan dan dilihat, yaitu dengan memberikan persepsi baik terhadap pembelajaran maupun media yang akan digunakan dalam pembelajaran. Dengan pemanfaatan teknologi maka akan meminimalisir dalam penggunaaan kertas serta dapat digunakan dimanapun dan kapanpun. Sementara dalam penggunaan kertas maka akan terjadi pemborosan dalam penggunaan kertas serta dengan $e$ module materi cermin cekung dapat digunakan dimanapun dan kapanpun. Dengan itu dalam penelitian ini bertujuan untuk melihat hubungan persepsi mahasiswa terhadap penggunaan $e$-module materi cermin cekung dengan keterampilan proses sains (KPS) dasar mahasiswa.

\section{METODE}

Metode yang digunakan dalam penelitian ini adalah metode penelitian asosiatif kuantitatif dengan desain penelitian korelasional. Correlational design is a procedure in which researchers measure the relationship between two or more variables using statistical analysis correlational procedures [19]. Penelitian korelasional adalah penelitian yang menghubungkan antara dua variabel atau lebih [20]. Desain penelitian ini digunakan karena sesuai dengan tujuan dari penelitian ini yaitu untuk mengetahui hubungan dari keterampilan proses sains dasar mahasiswa dengan persepsi mahasiswa dalam penggunaan e-module pada materi cermin cekung. 
Variabel yang digunakan dalam penelitian ini adalah variabel keterampilan proses sains dasar mahasiswa yang terdiri dari indikator observasi, komunikasi, klasifikasi, pengukuran, kesimpulan, prediksi dan menggunakan variabel persepsi mahasiswa dalam penggunaan $e$ module pada materi cermin cekung. Penelitian ini juga menggunakan teknik statistik deskriptif untuk menganalisis data [21]. Data yang digunakan dalam penelitian ini adalah data kuantitatif. Teknik penelitian yang digunakan adalah teknik purposive sampling. Purposive sampling adalah sampel yang dihasilkan dengan mengambil subjek bukan berdasarkan strata, acak atau regional tetapi berdasarkan pertimbangan tertentu [22]. Instrumen yang digunakan adalah instrumen keterampilan proses sains dasar mahasiswa yang terdiri dari 48 pernyataan dan instrumen persepsi mahasiswa terhadap e-module pada materi cermin cekung yang terdiri dari 20 pertanyaan. Responden terdiri dari 34 mahasiswa pendidikan fisika Universitas Jambi yang sedang mengontrak mata kuliah fisika dasar. Instrumen yang digunakan dalam penelitian ini menggunakan skala likert. Skala likert digunakan untuk mengukur sikap, pendapat, dan persepsi seseorang atau sekelompok orang tentang fenomena sosial [23]. Skala likert dalam penelitian ini pada keterampilan proses sains dasar mahaiswa yaitu terdiri dari 4 kategori. Setelah data dihasilkan selanjutnya data dianalisis dengan menggunakan statistik deskriptif, inferensial dengan uji interval dan analisis correlation dengan menggunakan SPSS. Rentang pada keterampilan proses sains dasar mahaiswa dengan persepsi mahasiswa terhadap $e$ module pada materi cermin cekung dapat dilihat pada tabel berikut:

Tabel. 1 Rentang Interval pada Keterampilan Proses Sains Dasar Mahasiswa dengan Persepsi Mahasiswa Terhadap E-Module Materi Cermin Cekung

\begin{tabular}{lllllll}
\hline \multicolumn{2}{c}{ Category } & Persepsi & \multicolumn{5}{c}{ KPS Dasar } \\
\cline { 4 - 7 } & & Observasi & Komunikasi & $\begin{array}{l}\text { Klasifikasi } \\
\text { dan Prediksi }\end{array}$ & Mengukur & Kesimpulan \\
\hline Sangat tidak baik & $20-40$ & $8.0-14.0$ & $2.0-3.5$ & $1.00-1.75$ & $3.00-5.25$ & $6.0-10.5$ \\
Tidak baik & $41-60$ & $14.1-20.0$ & $3.6-5.0$ & $1.76-2.50$ & $5.25-7.50$ & $10.6-15.0$ \\
Baik & $61-80$ & $20.1-26.0$ & $5.1-6.5$ & $2.51-3.25$ & $7.51-9.75$ & $15.1-19.5$ \\
Sangat baik & $81-100$ & $26.1-32.0$ & $6.6-8.0$ & $3.26-4.00$ & $9.76-12.00$ & $19.5-24.0$ \\
\hline
\end{tabular}

\section{HASIL DAN PEMBAHASAN}

Hubungan pada keterampilan proses sains dasar mahasiswa dengan persepsi mahasiswa terhadap e-module pada materi cermin cekung dapat dilihat berdasarkan hasil dari analisis data yang telah diperoleh. Hasil analisis data yang dilakukan akan memberikan informasi sesuai dengan tujuan dari penelitian ini. Data yang telah dianalisis menggunakan statistik deskriptif dapat dilihat pada Tabel 2 berikut:

Tabel 2. Hasil Analisis Statistik Deskriptif Keterampilan Proses Sains Dasar Mahasiswa terhadap E-Module Materi Cermin Cekung

\begin{tabular}{llllll}
\hline \multicolumn{2}{c}{ Classification } & Mean & Median & Min & Max \\
\cline { 2 - 5 } KPS Dasar & Class & 28.9 & 29.0 & 26.0 & 32.0 \\
& Observasi & 7.4 & 8.0 & 6.0 & 8.0 \\
& Komunikasi & 3.6 & 4.0 & 3.0 & 4.0 \\
& Klasifikasi & 8.2 & 9.0 & 5.0 & 12.0 \\
& Pengukuran & 16.5 & 18.0 & 8.0 & 24.0 \\
& Kesimpulan & 2.6 & 3.0 & 1.0 & 4.0 \\
\hline
\end{tabular}


Berdasarkan Tabel 2 yang dihasilkan bahwa nilai dari statistik deskriptif keterampilan proses sains dasar mahasiswa terhadap e-module materi cermin cekung untuk nilai terbesar yaitu nilai mean sebesar 28.9 pada indikator observasi, nilai median sebesar 29.0 pada indikator observasi, nilai dari minimum sebesar 26.0 pada indikator observasi dan nilai maksimum sebesar 32.0 pada indikator observasi. Selanjutnya untuk persentase keterampilan proses sains dasar mahaiswa yaitu dapat dilihat pada Tabel 3.

Tabel 3. Persentase Keterampilan Proses Sains Dasar Mahasiswa

\begin{tabular}{|c|c|c|c|c|c|c|}
\hline \multirow[t]{8}{*}{ KPS Dasar } & \multirow[t]{2}{*}{ Class } & \multicolumn{4}{|c|}{$\%$} & \multirow[t]{2}{*}{ Total } \\
\hline & & Sangat baik & Baik & $\begin{array}{l}\text { Tidak } \\
\text { baik }\end{array}$ & Sangat tidak baik & \\
\hline & Observasi & 38.2 & 11.8 & 35.3 & 14.7 & 100 \\
\hline & Komunikasi & 29.4 & 23.5 & 23.5 & 23.5 & 100 \\
\hline & Klasifikasi & 41.2 & 11.8 & 11.8 & 35.3 & 100 \\
\hline & Pengukuran & 32.4 & 26.5 & 20.6 & 20.6 & 100 \\
\hline & Kesimpulan & 26.5 & 32.4 & 20.6 & 20.6 & 100 \\
\hline & Prediksi & 23.5 & 35.3 & 20.6 & 20.6 & 100 \\
\hline
\end{tabular}

Persentase keterampilan proses sains dasar yang dimilki mahasiswa dapat dilihat pada Tabel 3, dengan persentase tertinggi terdapat pada indikator klasifikasi yaitu sebesar $41.2 \%$ dengan kategori sangat baik. Selanjutnya untuk nilai statistik deskriptif persepsi mahasiswa terhadap $e$ module pada materi cermin cekung $e$ module dapat dilihat pada Tabel 4 berikut:

Tabel 4. Hasil Analisis Statistik Deskriptif Persepsi Mahasiswa terhadap E-Module pada Materi Cermin Cekung

\begin{tabular}{|c|c|c|c|c|c|c|c|c|}
\hline \multicolumn{4}{|c|}{ Classification } & \multirow[t]{2}{*}{ Mean } & \multirow[t]{2}{*}{ Median } & \multirow[t]{2}{*}{ Min } & \multirow[t]{2}{*}{$\operatorname{Max}$} & \multirow[t]{2}{*}{$\%$} \\
\hline & Interval & Category & Total & & & & & \\
\hline Persepsi & $20-40$ & Sangat tidak baik & 0 & & & & & 0 \\
\hline & $41-60$ & Tidak baik & 0 & 66.8 & 63.0 & 38.0 & 100.0 & 0 \\
\hline & $61-80$ & Baik & 13 & 00.0 & 0.0 & 30.0 & 100.0 & 38.2 \\
\hline & $81-100$ & Sangat baik & 21 & & & & & 61.8 \\
\hline Total & & & 34 & & & & & 100.0 \\
\hline
\end{tabular}

Berdasarkan Tabel 4 yang dihasilkan bahwa nilai dari statistik deskriptif persepsi mahasiswa terhadap e-module pada materi cermin cekung untuk nilai mean yaitu 66.8 , nilai median 63.0, nilai dari minimum 38.0 dan nilai maksimum adalah 100.0 serta untuk persentase keterampilan proses sains dasar mahaiswa yaitu sebesar $61.8 \%$. Untuk hasil analisis data hubungan keterampilan proses sains dasar mahasiswa dengan persepsi mahasiswa terhadap $e$ module pada materi cermin cekung dapat dilihat pada Tabel 5 berikut:

Tabel 5. Hubungan KPS Dasar Mahasiswa dengan Persepsi Mahasiswa terhadap E-Module pada Materi Cermin Cekung

\begin{tabular}{lc}
\hline \multicolumn{2}{c}{ Hubungan KPS Dasar dengan Persepsi } \\
\hline Pearson Correlation & 0.958 \\
Sig. (2-tailed) & 0.000
\end{tabular}

Berdasarkan Tabel 5 yang dihasilkan bahwa hasil analisis data hubungan keterampilan proses sains dasar mahaiswa dengan persepsi mahasiswa terhadap $e$ - 
module pada materi cermin cekung dengan pearson correlation 0.958 dan signifikansi sebesar 0.000. Hasil data yang telah dianalisis menghasilkan bahwa pada keterampilan proses sains dasar mahasiswa terhadap e-module pada materi cermin cekung menghasilkan persentase sebesar $38.2 \%$ pada indikator observasi dengan kategori sangat baik. Science process skills are important for students to improve their ability to use scientific methods and gain new knowledge. Because science process skills can be developed through the practical activities needed to guide the laboratory with the concept of thinking skills that can improve science process skills [24]. Penggunaan e-module maka akan memberikan dampak positif terhadap keterampilan proses sains dasar mahasiswa. Keterampilan dasar yang dimiliki mahasiswa yaitu terdiri dari indikator observasi, komunikasi, klasifikasi, pengukuran, kesimpulan, prediksi. Berdasarkan hasil yang telah diperoleh maka pada masing-masing indikator keterampilan proses sains dasar mahasiswa dapat dikatakan bahwa, mahasiswa telah mampu melakukan kegiatan praktikum dengan baik dan dapat mengamati dengan cermat pada setiap kegiatan praktikum dilaksanakan, mampu mengkomunikasikan apa saja yang terkait dengan kegiatan praktikum berdasarkan apa yang dilihat dan dilakukan, mampu mengklasifikasikan, mampu mengukur berapa nilai dari bayangan pada cermin cekung serta bagaimana bayangan terbentuk saat benda diletakkan dengan memvariasikan ruang pada cermin cekung, dan mampu memberikan kesimpulan serta prediksi pada kegiatan praktikum cermin cekung.

Hasil persentase persepsi mahasiswa terhadap e-module pada materi cermin cekung adalah sebesar $21 \%$ dengan kategori sangat baik. Sehingga dapat dikatakan bahwa mahasiswa termotivasi dan berminat dalam penggunaan panduan praktikum materi cermin cekung. Without motivation, there is nothing like learning. 2) Motivation functions as a guide. This means directing the action to achieve the desired goal. 3) Motivation functions as a driver, functions as a machine for cars, a measure of motivation will determine the speed or slow pace of a job [25]. Minat yang ada pada mahasiswa dapat ditingkatkan dengan dukungan orang tua. Minat di bidang sains termasuk tugas yang penting bagi setiap orang tua untuk mendukung [26]. Penggunaan e-module materi cermin cekung akan memberikan dampak positif pada mahasiswa salah satunya adalah motivasi, dengan termotivasinya mahasiswa dalam melakukan praktikum maka akan terwujudnya tujuan praktikum yang telah ditentukan. Selanjutnya hubungan pada keterampilan proses sains dasar mahasiswa dengan persepsi mahasiswa terhadap penggunaan $e$-module materi cermin cekung dapat dilihat pada Tabel 5 . Berdasarkan nilai signifikansi yang dihasilkan maka dapat dikatakan bahwa hubungan pada keterampilan proses sains dasar mahasiswa dengan persepsi mahasiswa terhadap e-module pada materi cermin cekung adalah sangat kuat. Sehingga apabila nilai keterampilan proses sains dasar mahasiswa bernilai baik maka persepsi mahasiswa terhadap e-module pada materi cermin cekung juga akan memiliki persepsi yang baik juga dengan berasumsi bahwa persepsi mahasiswa dengan e-module maka akan termotivasi dalam melakukan praktikum. The attitude of a student's success determines the material absorbed in the learning process. The success of students to absorb well the teaching material delivered in the learning process by the teacher will lead to positive learning outcomes in every natural science of students [27]. Penggunaan e-module maka akan lebih efektif dan efesien. Dengan dampak bahwa dapat 
meminimalisir dalam penggunaan kertas serta dapat digunakan dimanapun dan kapanpun.

\section{SIMPULAN}

Berdasarkan penelitian yang telah dilakukan dapat disimpulkan bahwa pada keterampilan proses sains dasar mahasiswa terhadap e-module pada materi cermin cekung menghasilkan persentase $41.2 \%$ dengan kategori sangat baik dan persepsi mahasiswa terhadap $e$-module pada materi cermin cekung adalah sebesar $61.8 \%$ dengan kategori sangat baik. Berdasarkan nilai signifikansi yang dihasilkan maka dapat dikatakan bahwa hubungan pada keterampilan proses sains dasar mahasiswa dengan persepsi mahasiswa terhadap $e$ module pada materi cermin cekung adalah sangat kuat dengan pearson correlation 0.958 dan signifikansi sebesar 0.000 .

\section{DAFTAR PUSTAKA}

[1] D. A. Kurniawan, Astalini, and D. K. Sari. "An Evaluation Analysis Of Students' Attitude Towards Physics Learning At Senior High School”. $J$. Chem. Inf. Model., vol. 23, no. 1, pp. 26-35, 2013.

[2] A. Astalini, D. A. Kurniawan, dan L. Z. Nurfarida. "Deskripsi Sikap Siswa SMA di Batanghari Berdasarkan Indikator Normalitas Ilmuwan, Adopsi dari Sikap Ilmiah, Ketertarikan Memperbanyak Waktu, dan Ketertarikan Berkarir di Bidang Fisika". J. Ris. dan Kaji. Pendidik. Fis., vol. 5, no. 2, pp. 73, 2018.

[3] Maison, Astalini, D. A. Kurniawan, dan L. R. Solihah. "Deskripsi Sikap Siswa SMA Negeri Pada Mata Pelajaran Fisika". Edusains, vol. 10, no. 1, pp. 160-167, 2018.

[4] A. Susilo, W. Sunarno, dan S. Sukarmin. "Pembelajaran Fisika Menggunakan Metode Inkuiri Terbimbing dan Inkuiri Bebas Termodifikasi Berdasarkan
Kompendium Al-Qur'an Ditinjau dari Kedisiplinan Belajar dan Sikap Ilmiah". Inkuiri J. Pendidik. IPA, vol. 7, no. 2, pp. 160, 2018.

[5] Astalini, D. A. Kurniawan, R. Perdana, and H. Pathoni. "Identifikasi Sikap Peserta Didik terhadap Mata Pelajaran Fisika di Sekolah Menengah Atas Negeri 5 Kota Jambi". Unnes Phys. Educ. J., vol. 8, no. 1, pp. 35, 2019.

[6] A. Astalini, D. A. Kurniawan, dan S. Sumaryanti. "Sikap Siswa terhadap Pelajaran Fisika di SMAN Kabupaten Batanghari." JIPF (Jurnal Ilmu Pendidik. Fis.), vol. 3, no. 2, pp. 59, 2018.

[7] J. P. Herron and M. N. Hennessey. "Evaluation of Student's Attitude Toward Science in Indonesia". Open J. Educ. Res., vol. 3, no. 2, pp. 3952, 2019.

[8] A. Astalini dan D. A. Kurniawan. "Pengembangan Instrumen Sikap Siswa Sekolah Menengah Pertama terhadap Mata Pelajaran IPA". J. Pendidik. Sains, vol. 7, no. 1, pp. 17, 2019.

[9] D. Darmaji, D. A. Kurniawan, dan A. Suryani. "Effectiveness of Basic Physics II Practicum Guidelines Based On Science Process Skills." JIPF (Jurnal Ilmu Pendidik. Fis.), vol. 4, no. 1, pp. 693, 2019.

[10] D. Darmaji, D. A. Kurniawan, H. Parasdila, dan I. Irdianti. "Deskripsi Keterampilan Proses Sains Mahasiswa pada Materi Termodinamika". Berk. Ilm. Pendidik. Fis., vol. 6, no. 3, pp. 345353, 2018.

[11] D. Darmaji, D. A. Kurniawan, A. Suryani, dan A. Lestari. "An Identification of Physics Pre-Service Teachers' Science Process Skills Through Science Process SkillsBased Practicum Guidebook". J. Ilm. Pendidik. Fis. Al-Biruni, vol. 7, no. 
2, pp. 239, 2018.

[12] I. Darmaji, Kurniwan. "Physics Education Students' Science Process Skills in Universitas Jambi". Int. J. Eval. Res. Educ., vol. 8, no. 2, pp. 293-298, 2019.

[13] A. Asrial, S. Syahrial, D. A. Kurniawan, dan N. Amalina. "Analisis Hubungan Kompetensi Bahasa Indonesia terhadap Kompetensi Pedagogik Mahasiswa Pendidikan Guru Sekolah Dasar". Prem. Educ. J. Pendidik. Dasar dan Pembelajaran, vol. 9, no. 1, pp. 1-8, 2019.

[14] D. Darmaji, D. A. Kurniawan, dan A. Lestari. "Deskripsi Keterampilan Proses Sains Mahasiswa Pendidikan Fisika pada Praktikum Suhu dan Kalor". J. Ris. dan Kaji. Pendidik. Fis., vol. 5, no. 2, pp. 68, 2018.

[15] S. Wang, J. Wan, D. Li, and C. Zhang. "Implementing Smart Factory of Industrie 4.0: An Outlook". Int. J. Distrib. Sens. Networks, vol. 3, no. 2, pp. 1-10, 2016.

[16] A. Astalini, D. A. Kurniawan, R. Melsayanti, dan A. Destianti. "Sikap Terhadap Mata Pelajaran Ipa Di SMP Se-Kabupaten Muaro Jambi”. Lentera Pendidik. J. Ilmu Tarb. dan Kegur., vol. 21, no. 2, pp. 214, 2018.

[17] A. Astalini, D. Darmaji, W. Kurniawan, K. Anwar, and D. A. Kurniawan. "Effectivenes of Using E-Module and E-Assessment". Int. J. Interact. Mob. Technol., vol. 13, no. 09, pp. 21, 2019.

[18] A. Yulliani dan A. Suryadi. "Persepsi Siswa tentang Tokoh Dewi Sartika dalam Pembelajaran Sejarah di SMAN 1 Dukun Tahun Ajaran 2017/2018". Hist. Pedagog., vol. 7, no. 2, pp. 159-166, 2018.

[19] Creswell, JW. Research Design Pendekatan Kualitatif, Kuantitaif dan Mixed Cetakan ke-2. Yogyakarta: Pusaka Belajar, 2012.
[20] S. Arikunto. Prosedur Penelitian Suatu pendekatan Praktek. Jakarta: Rineka Cipta, 2010.

[21] Sugiyono. Metode Penelitian Kombinasi. Yogyakarta: Alfabeta, 2018.

[22] J. Heridiansyah. "Pengaruh Advertising terhadap Pembentukan Brand Awareness serta Dampaknya pada Keputusan Pembelian Produk Kecap Pedas ABC". J. STIE Semarang, vol. 4, no. 2, pp. 53-73, 2012.

[23] Sugiyono. Metode Penelitian Kombinasi. Yogyakarta: Alfabeta, 2013.

[24] D. Darmaji, D. A. Kurniawan, A. Astalini, A. Lumbantoruan, and S. C. Samosir. "Mobile Learning in Higher Education for The Industrial Revolution 4.0: Perception and Response of Physics Practicum". Int. J. Interact. Mob. Technol., vol. 13, no. 09, pp. 4, 2019.

[25] Astalini, D. A. Kurniawan, U. Sulistiyo, R. Perdana, and Susbiyanto. "E-assessment Motivation in Physics Subjects for Senior High School". Int. J. online Biomed. Eng., vol. 15, no. 11, pp. 415, 2019.

[26] D. A. Kurniawan, Astalini, dan L. Anggraini, "Evaluasi Sikap Siswa SMP terhadap IPA di Kabupaten Muaro Jambi”. Ilm. Didakt., vol. 19, no. 1, pp. 124-139, 2018.

[27] Astalini, Darmaji, D. A. Darmaji, Kurniawan, and Destianti. "Description of the Dimensions Attitudes Towards Science in Junior High School at Muaro Jambi". IJSBAR, vol. 47, no. 1, pp. 1-11, 2019. 